IP Periodica Polytechnica Civil Engineering

\author{
59(3), pp. 347 360 2015 \\ DOI: $10.3311 /$ PPci.7852 \\ Creative Commons Attribution (1) \\ RESEARCH ARTICLE
}

\section{Flow and Dispersion Phenomena in a Simplified Urban Square}

\author{
Márton Balczó, Tamás Lajos
}

Received 03-12-2014, revised 25-03-2015, accepted 14-04-2015

\begin{abstract}
The paper deals with wind conditions and air pollutant dispersion in urban squares. We focus on the phenomenological description of principal flow phenomena appearing in squares and on the understanding of basic transport mechanisms. For this purpose a simplified square with rectangular layout was investigated by means of wind tunnel tests applying sand erosion technique and tracer gas concentration measurements. The MISKAM CFD model was used to simulate flow and dispersion at various wind directions. The analysis of results allowed the identification of flow structures appearing in the square, the interaction of which is responsible for the inhomogeneous wind speed and concentration distribution in the square. Most importantly, separation zones of buildings located on the upstream side of the square cause low local wind speeds and strong vertical pollutant transport. Separation zones in front of the downstream building blocks induce higher local wind speeds and improve the removal of pollutants.
\end{abstract}

\section{Keywords}

urban square $\cdot$ flow structures $\cdot$ pollutant dispersion $\cdot$ wind tunnel $\cdot$ sand erosion $\cdot$ CFD

\section{Márton Balczó}

Department of Fluid Mechanics, Faculty of Mechanical Engineering, Budapest University of Technology and Economics, Múegyetem rkp. 3, H-1111 Budapest, Hungary

e-mail: balczo@ara.bme.hu

\section{Tamás Lajos}

Department of Fluid Mechanics, Faculty of Mechanical Engineering, Budapest University of Technology and Economics, Múegyetem rkp. 3, H-1111 Budapest, Hungary

e-mail: lajos@ara.bme.hu

\section{Introduction}

Despite numerous efforts on the reduction of vehicle emissions in the past decades, traffic related air pollution remains a major environmental issue in densely populated built-up areas, where buildings are obstructing the atmospheric boundary layer flow and are thus modifying the dispersion of pollutants. There is a wide coverage of the subject in the literature, of which review papers [1-4] give an overview. The applied methods range from on-site and wind tunnel measurements to different kinds of numerical modelling. The influence of buildings has been investigated using geometries of various complexity levels (single buildings, street canyons, street intersections, regular arrangement of building blocks, semi-idealised and real urban areas). The simpler setups made it easy to identify the principal flow structures influencing the overall flow field and transport processes, like separation bubbles, corner vortices and street canyon vortices.

Urban squares, defined as free spaces bordered by buildings from all four sides were rather seldom studied, despite their frequent occurrence in urban areas, and their role in urban life. In case traffic is passing the square on at least one side, high pollutant concentrations can be expected. Examples of such squares are depicted in Fig. 1] A quick survey on satellite maps of European cities shows that squares differ in size, in length to width $(l / w)$ ratio, in the number and the location of the connecting streets, and whether tree plantings are present.

The wind tunnel and CFD study of [5] investigated a semicircular square and found recirculation zones behind the upstream located buildings of the square. [6] showed using CFD simulations that depending on wind direction, locally released pollutants can be trapped in the separation bubbles downstream those buildings and concentration distribution in the square is quite inhomogeneous. Further measurement data is available from wind tunnel data sets like the 'Michel-Stadt' semiidealised urban dataset of [7] which also include squares, among other features of an urban geometry. So there is experimental and numerical data available on the flow and dispersion field in squares [8-10]. However, the specialities of the flow in the squares were not separately addressed in the aforementioned 
studies. New measurement data with higher spatial resolution could improve our understanding of the flow and dispersion phenomena in squares.

With the scope of the future in-depth study of a real urban square, József Nádor Square in downtown Budapest (coordinates $47.498 \mathrm{~N}, 19.050 \mathrm{E}$, see Fig. 1 b), we decided to create a simplified square model which will make it easier to identify those flow phenomena which might be present in other squares of similar size, too. Thus, the main proportions of the simplified square were determined on the basis of the actual square. However, building heights were set to uniform and street connections were chosen to be symmetric.

The idealised geometry is depicted in Fig. 2. The place is surrounded by building blocks of the same height of $h=30 \mathrm{~m}$, with block width $b=50 \mathrm{~m}$. Building blocks at the eastern and western side are of triple length $(150 \mathrm{~m})$, the connecting streets are only $w=15 \mathrm{~m}(0.5 h)$ wide. The square, which results from these dimensions, has a length to height $(l / h)$ ratio of 6 along its longer side and 2.67 along its shorter side.

The major source of pollution in József Nádor Square is a 4lane street bordering the square in the north with heavy traffic, while other traffic in the square is negligible. Thus in the simplified model, pollutant emissions were modelled with a single line source.
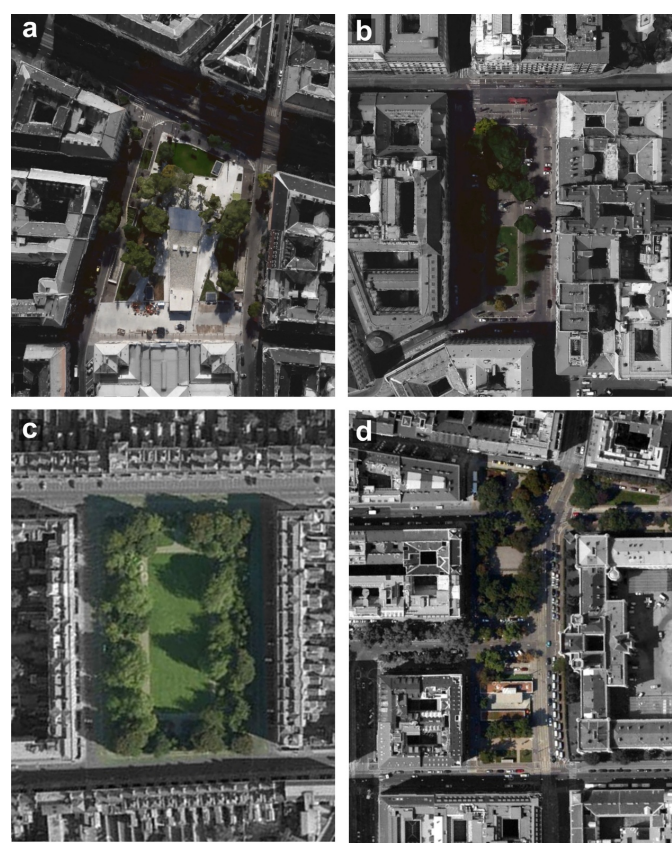

Fig. 1. Typical urban squares: a) Rákóczi Square, Budapest b) József Nádor Square, Budapest c) Fitzwilliam Square, Dublin d) Schlick Square, Vienna.

\section{Experimental setup}

\subsection{Wind tunnel and boundary layer measurements}

The wind tunnel experiments were performed in an NPL-type (Eiffel-type) wind tunnel with a closed test section of $0.5 \times 0.5 \mathrm{~m}$ and $18 \mathrm{~m} / \mathrm{s}$ highest velocity (Fig. 3). The test section has transparent windows, allowing access for laser based measurements and photography. Between the inlet contraction and the test sec- tion spires and roughness elements are situated for the simulation of the atmospheric boundary layer (ABL). The model of the simplified square has a scale of 1:650 meaning that the building height $h$ is in full scale $30 \mathrm{~m}$ and in model scale $46 \mathrm{~mm}$. The model is located on a turntable of $0.5 \mathrm{~m}$ diameter.

Velocity measurements were performed using a twocomponent Laser-Doppler Velocimeter system, which gained access to the flow through the side window, thus the $u$ stream wise and the $w$ vertical velocity components could be measured. The system utilises a $300 \mathrm{~mW}$ Argon-Ion laser source, the focal length of the back-scatter-mode laser optics was $363 \mathrm{~mm}$. The measurement volume (the ellipsoidal beam cross section, in which the measurement occurs) is thus adjusted horizontally, and has a diameter of $90 \mu \mathrm{m}$ and a length of $1.3 \mathrm{~mm}$, which gives a spatial resolution high enough for this model scale. Oil seeding particles were introduced into the flow in front of the wind tunnel inlet. Light reflected back from the particles into the optics is led to photomultipliers and then digitised and analysed by TSI FSA3500 DSP-based signal processing unit. Burst frequencies are determined by autocorrelation. Burst velocities were weighted with gate time to get average velocities. Sample rate was around $500 \mathrm{~Hz}$ in average.

The generated boundary layer was checked in several vertical profile measurements. The results are depicted in Fig. 4 and 5. Fig. 4 shows the boundary layer profile in the vertical symmetry plane of the wind tunnel. A power law curve was fitted to the measured points:

$$
u(z)=u_{h} \cdot\left(\frac{z-d_{0}}{h-d_{0}}\right)^{\alpha}
$$

where $\alpha$ is the exponent, $h$ is the reference height, $u_{h}$ is the mean velocity at the reference height and $d_{0}$ is the displacement height. The parameter $\alpha=0.4$ corresponds to very rough, urbantype surface according the VDI guideline $3783 / 12$ [11]. It must be noted that the profile is elevated with $15 \mathrm{~m}(0.5 \mathrm{~h})$ off the ground which is proper in a densely built urban environment.

Turbulence intensity $I_{u}=\sigma_{u}(z) / \bar{u}(\mathrm{z})$ is also evaluated, and up to a height of $60 \mathrm{~m}$ full scale, the measured turbulence intensity profile lies within the limits of the VDI guideline.

In a small, closed test section wind tunnel like the one applied here, the effect of sidewalls and the homogeneity of the ABL profile is of concern. Thus, the velocity distribution in the whole cross section was measured by LDV as shown in Fig. 5 The measurement results prove that in lateral $(y$-) direction about $80 \%$ ( $260 \mathrm{~m}$ in full scale) of the ABL flow is undisturbed by sidewalls and it is quite homogeneous; in the remaining $20 \%$, however, a wall boundary layer can be observed. As a consequence, at northerly wind direction the flow around the square model with $180 \mathrm{~m}$ width is not influenced by the wall. At northwesterly and westerly wind, the outer corners of the building blocks are close to the wind tunnel wall and thus certainly affected by the sidewall. Despite of this, the square itself is in homogeneous boundary layer at all wind directions. 


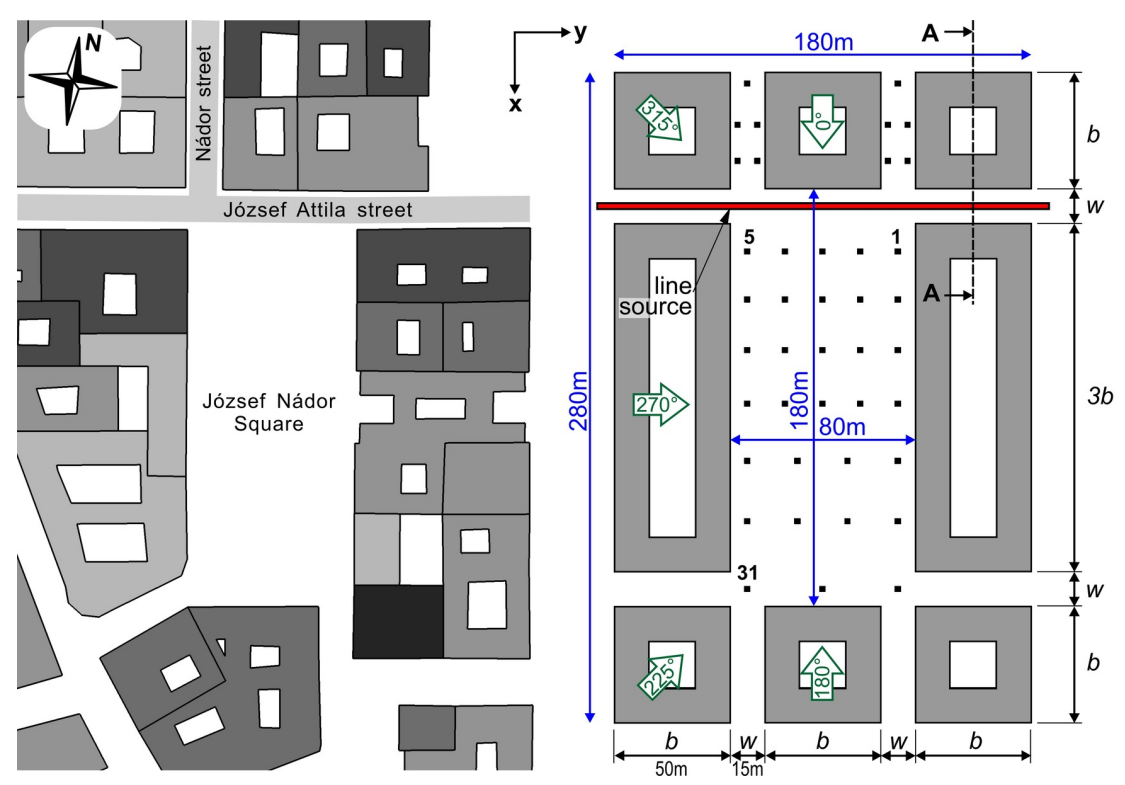

Fig. 2. Left: geometry of the real square. Buildings coloured by height; tration measurement locations indicated by black dots. Green arrows show wind right: view of the simplified square model, with line source in red and concen- directions.

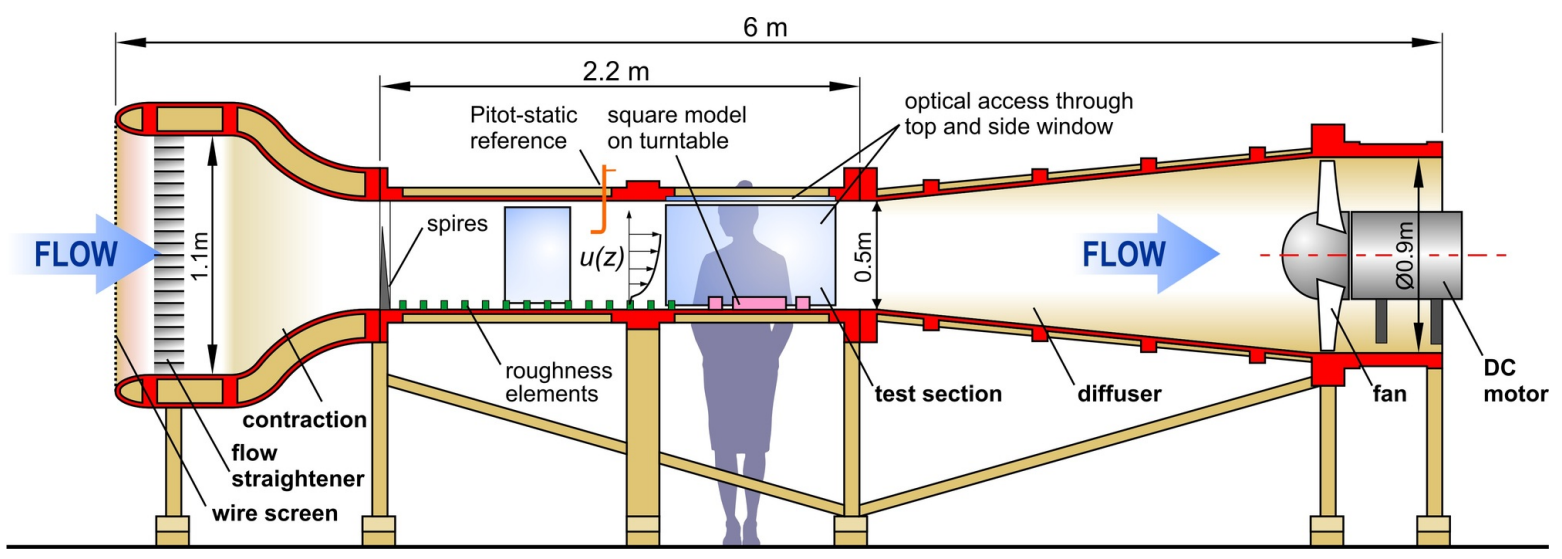

Fig. 3. The NPL type wind tunnel with its main components, and the measurement setup with the boundary layer generating elements and the wind tunnel
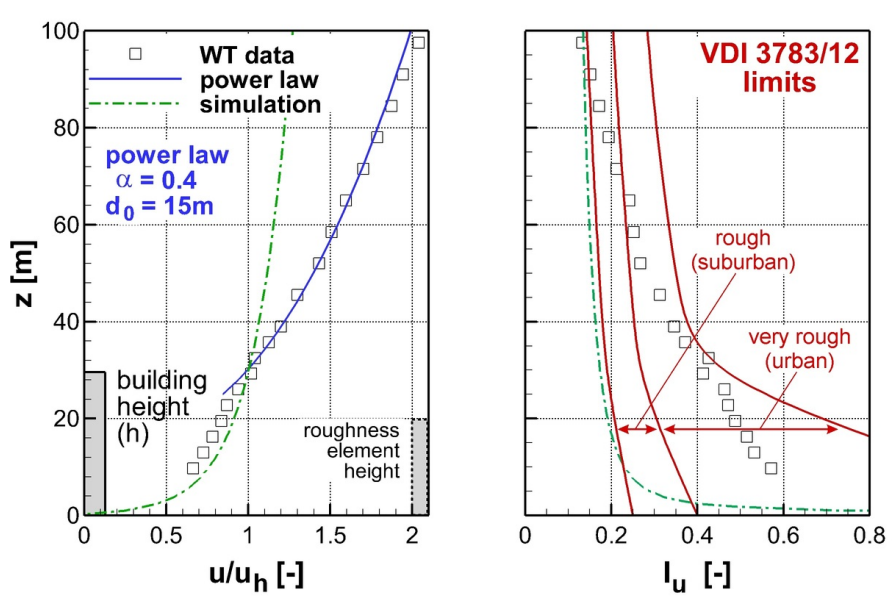

Fig. 4. Left: the vertical profile of dimensionless mean velocity $u_{d}=$ $u(z) / u_{h}$ of the approach flow in the symmetry plane of the wind tunnel $(\mathrm{y}=0)$. Right: vertical profile of turbulence intensity $I_{u}$ in the symmetry plane. Height is given in full scale. model placed in the test section.

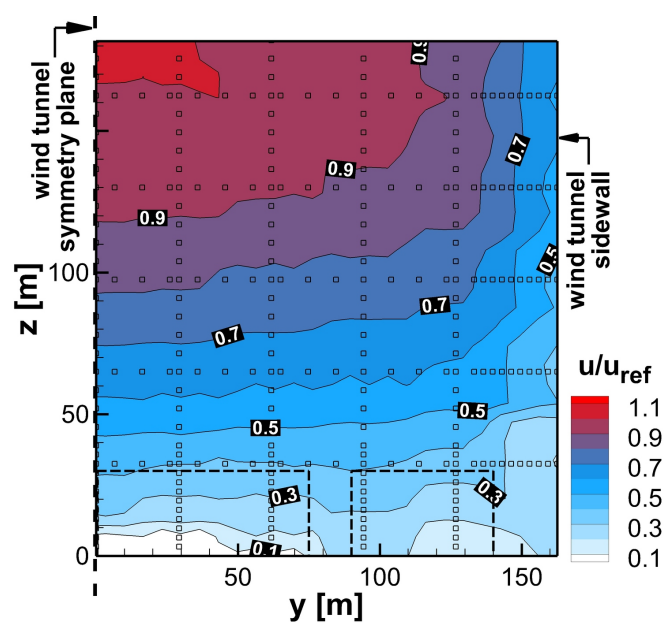

Fig. 5. Interpolated distribution of dimensionless mean velocity ud across the test section in transverse direction. Squares indicate measurement locations. Dashed line shows the extent of the building blocks surrounding the square at westerly wind direction. Length dimensions are given in full scale. 


\subsection{Sand erosion technique}

Sand erosion technique is a useful semi-quantitative tool for estimating wind conditions on the ground. Before measurement the black painted model's surface is covered by white sand of homogeneous corn size. With step wise increase of the wind tunnel wind speed the sand is blown away, leaving the black surface to appear. The model is photographed from above at each velocity step, and contours of sand are digitised and assigned to the actual wind speed. With a calibration measurement beforehand, the method can give quantitative results. The method was first described by [12]. Quantitative analysis was applied first by [13] using digital image processing of the photographs taken. Since then, the method was used in a number of studies: [14] investigated snow erosion and deposition around an Antarctic base in complex terrain. [15] applied the method for wind resource assessment in a mountain area. Several researchers have shown that the entrainment of sand particles is a complex phenomenon, not only influenced by the average wind speed above the surface, but also by the gustiness of wind. According to [13], the sand erosion contour map is approximately proportional to the sum of the mean speed and its standard deviation. This is advantageous for wind comfort studies, as wind comfort is depending on a similar quantity. The very thorough study of [16] on all aspects of this technique indicates that the transport of sand particles is influenced by several effects which increase the uncertainty of the method. Despite these concerns, high speed locations are very well shown by sand erosion, which makes this method suitable to a preliminary screening of a large investigation area to identify spots of interest, which can be later investigated by using more sophisticated measurement techniques.

In the current study, we investigated the surface wind conditions of the simplified square model using sand erosion technique at three wind directions (North, West, Northwest: 0, 270, 315 degree to North). At the beginning, we performed a calibration measurement, in which a sand-covered black flat plate was placed in the ABL flow. Sand corn size was between 0.16 $0.25 \mathrm{~mm}$. Wind speed was measured $5 \mathrm{~mm}$ (approx. $3 \mathrm{~m}$ in full scale) above the plate $\left(u_{3 m}\right)$ using a Pitot tube. Wind tunnel speed was increased in small steps and in each step, after 5 min settling time, a photo was taken. The critical local mean wind speed at which the sand on the plate was carried away, was $u_{3 m}=3.93 \mathrm{~m} / \mathrm{s}$. During the sand erosion testing of the square, wind tunnel speed and thus, reference wind speed at building height $u_{h}$ was also increased step-by-step. Considering the same level of gustiness as at the calibration and at the measurement, sand transport is supposed to occur at the above mentioned $3.93 \mathrm{~m} / \mathrm{s}$ mean wind speed, thus the normalised mean wind velocity $v_{m d}=u_{3 m} / u_{h}$ at $3.2 \mathrm{~m}$ full scale height can be determined as $3.93 / u_{h}$ for the areas from which sand has just been taken away. With increasing wind tunnel speed, $u_{h}$ varied from 1.8 to $6.5 \mathrm{~m} / \mathrm{s}$, and $v_{m d}$ from 2.2 to 0.6 . The photographs taken at various wind tunnel speeds could be summarised to a contour map of $v_{m d}$ using an in-house LabVIEW-based software.

\subsection{Tracer dispersion measurements}

The dispersion of air pollutants in the square was measured at five different wind directions $(0,180,225,270,315$ degree to North). Tracer gas was released continuously from the line source representing the pollutant emitting high-traffic road, and simultaneously, gas samples were collected in 41 sampling points distributed in the square and two connecting streets (see black dots in Fig. 2). Methane was used as tracer gas, and source strength $Q$ [g/s] was controlled using a digital mass flow controller. The construction of the line sources ensures homogeneous exhaust along the line following the construction proposed by [17]. Gas samples were collected simultaneously by an automatic 24-channel sampling system built from step motordriven sampling cylinders and magnetic valves and analysed by a slow flame ionization detector (FID) afterwards, and tracer concentration $c\left[\mathrm{~g} / \mathrm{m}^{3}\right]$ was determined. Sampling time was $60 \mathrm{~s}$. The system was calibrated with gas samples of known concentration. A detailed description of the sampling system can be found in [18].

The concentration measurement system was validated using a simple test case included in the VDI guideline 3783 / 12 [11], consisting of a line source placed into a crosswind boundary layer flow above flat terrain. The measured concentration decay downwind the source was inside the limits given by the guideline. The Reynolds number dependency of concentration results was also checked in measurements performed at various wind speeds and found to be negligible.

Results of the dispersion tests of the simplified square at three wind directions are given as normalised concentrations $c^{*}=c u_{h} h^{2} Q^{-1}$ on inverse-distance interpolated contour maps.

\section{Numerical setup}

\subsection{The MISKAM model}

The CFD model applied in the present study is the MISKAM microscale flow and dispersion model [19], which gained currency in urban planning and environmental assessment practice due to the relatively simple model set-up and to the fast code able to run on single processor PC. In contrast to highly sophisticated general-purpose academic CFD models, the model needs few and simple user inputs, and allows simple and rapid grid generation thus it can be used on operational basis by consultants or environmental agencies without much expertise in CFD.

The role of the CFD simulation in this study is to deliver 3D velocity and dispersion fields. The former can be used to show streamlines and detect vortex structures, thus explain the omnidirectional wind speed results captured with the sand erosion technique.

The model incorporates a Reynolds-averaged Navier-Stokes solver adopting the Boussinesq-approximations to eliminate sound waves with a modified $k-\varepsilon$ turbulence closure ([20] 
and [21]). A Cartesian grid of Arakawa-C type is used, in which buildings are represented as blockouts from the grid. The model also accounts for the influence of vegetation, which is handled by an additional drag force term in the motion equation and by additional turbulence-modifying terms in the equations for $k$ and $\varepsilon$. Dispersion of a passive pollutant is calculated by the Reynolds-averaged advection-diffusion equation using the wind field simulation results with turbulent Schmidt number equalling 0.741 .

The model has been thoroughly validated using reference data sets of different complexity. In [22] validation results according the VDI guideline VDI 3783/9 [23] is shown. [24] and [25] used the MUST data set for evaluation, testing with other data sets was performed by [26]. The vegetation model of MISKAM was evaluated by [27] and [28].

The MISKAM model's applicability to problems in urban environment has been shown by several authors [29-33]. The studies highlighted that MISKAM dispersion simulation results are in general close to observations, similar to other CFD models and superior to non-CFD models applied earlier - on cost of higher computational demand. Main flow features, separation bubbles, side and top vortices, street canyon vortices, channelling effects are fairly resolved in most cases. However also some deficiencies were discovered, mostly those which are typical for $k-\varepsilon$ turbulence models, i.e. lower wind speeds in separation bubbles, underestimated vertical and lateral velocity components near the obstacles, underestimation or suppression of some flow structures and overestimation of turbulent kinetic energy in stagnation points.

MISKAM was also used as wind field and turbulence input for other dispersion models [34][35] [36][37][38].

\subsection{Simulation setup}

The CFD simulation was run in full scale. Computational domain for the simulation of the simplified square model contains the buildings shown in Fig. 2, right and measures $878 \times 778 \times 180 \mathrm{~m}$, giving $10 \mathrm{~h}$ distance to the lateral and $5 \mathrm{~h}$ distance to the top boundaries, as required by the Best Practice Guideline [39].

The predefined boundary condition types of MISKAM (see [19]) were used: on the surfaces no-slip conditions were applied using wall functions, the roughness length on the surfaces was set to $0.01 \mathrm{~m}$. As a model in operational use, MISKAM needs a prescribed velocity at a reference height, and a roughness length of the environment (in our case $z_{0}=0.17 \mathrm{~m}$ ), as usually this is the data available from meteorological services for arbitrary locations. From these, an equilibrium inlet boundary layer profile is generated by MISKAM automatically. The velocity at the reference height of $h=30 \mathrm{~m}$ was prescribed, as measured in wind tunnel. Fig. 4 compares the measured and simulated inlet profiles. As obvious, MISKAM is not able to model elevated inlet boundary layer which developed in the wind tunnel over the roughness elements, the fitting is thus not perfect above building rooftop level. However, we expect that this difference will have a rather small impact on ventilation of the square, which is in the focus of our investigation. This expectation is well-founded, as [40] showed in case of a street intersection surrounded by buildings that the advective mass fluxes through the connecting streets are the most important contributors to the ventilation of the investigated area. Thus, the scaling of numerical results to the experimental results should ensure that advective mass flux through the streets is the same in both cases. This implies that velocity inlet profiles of CFD and measurement should most importantly agree at and below building height. The agreement of the profile in larger heights is desirable, but of secondary importance only.

Another argumentation applies to the difference between the measured and simulated turbulence inlet profile (Fig. 4 right). The wall function implemented in MISKAM limits the roughness length $z_{0}$ to $1 / 4$ of the thickness of the lowermost grid cell, in our case $0.7 \mathrm{~m}$, a consequence of which is lower turbulence intensity in the profile. This, however, applies for the inlet only, as turbulence levels in the square are supposed to depend in a large extent on the turbulence generated by the surrounding buildings themselves.

To check the dependency of the solution on grid resolution, four grids with varying grid densities have been created totalling to 117 thousand, 1 million, 2.5 million, and 5.3 million grid cells. Grid resolutions in the square were $5 \times 5 \times 4.3 \mathrm{~m}$, $2.5 \times 2.5 \times 1.5 \mathrm{~m}, 1.67 \times 1.67 \times 0.95 \mathrm{~m}$ and $1.25 \times 1.25 \times 0.7 \mathrm{~m}$, respectively. The narrow streets connecting to the square were resolved then by 3, 6, 9 and 12 cells in these grids. The simulations were run at northerly wind direction. Error analysis was performed afterwards for the calculated pollutant concentrations in the square: taking the wind tunnel results in measurement points 1 to 31 as reference, the normalised root mean square error (NRMSE) of the simulated concentrations was calculated. Furthermore, the hit rate $q$ was also determined.

$$
\begin{gathered}
\text { NRMSE }=\frac{\sum_{N} \sqrt{\left(c_{\text {sim }}^{*}-c_{W T}^{*}\right)^{2}}}{\sum_{N} c_{W T}^{*}} \\
q=\frac{1}{N} \sum_{N} n_{i} \text { with } \\
n_{i}=\left\{\begin{array}{l}
1 \text { if }\left|c_{\text {sim }}^{*}-c_{W T}^{*}\right|<D \cup \frac{\left|c_{s i m}^{*}-c_{W T}^{*}\right|}{c_{W T}^{*}}<W \\
0 \text { else }
\end{array}\right.
\end{gathered}
$$

with $W$ - allowed relative deviation $(25 \%)$ and $D-$ allowed absolute deviation $\left(c^{*}=0.5\right), c_{\text {sim }}^{*}$ - normalised concentration from the simulation, $c_{W T}^{*}-$ normalised concentration from the wind tunnel measurement.

A direct comparison of simulated and measurement results in Fig. 6, left suggests overall improving agreement with increasing grid resolution. The mesh dependency of NRMSE and $q$ is depicted in Fig. 6 , right. 

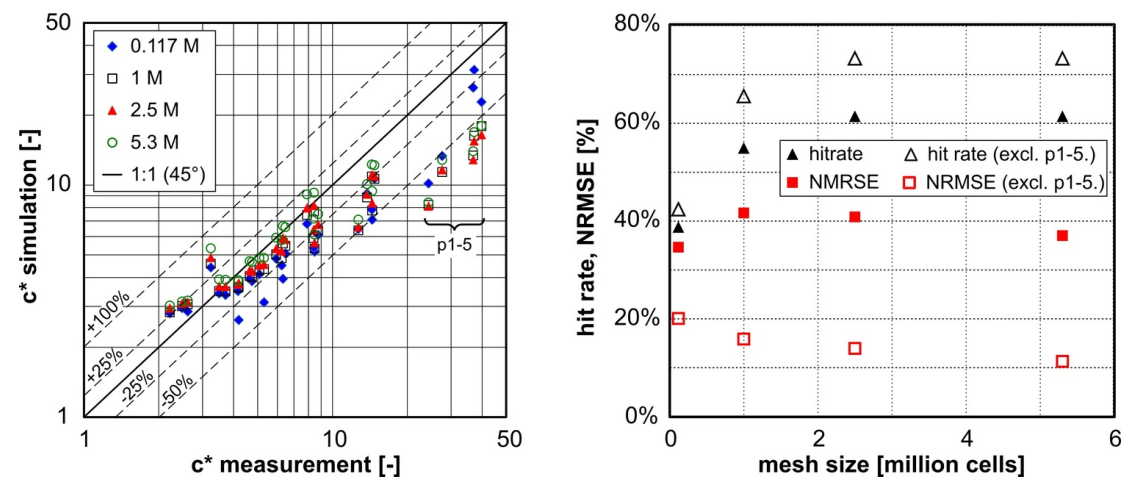

Fig. 6. Left: comparison of measured and simulated concentrations for various grid sizes. Right: NRMSE and hit rate of the calculated concentrations.
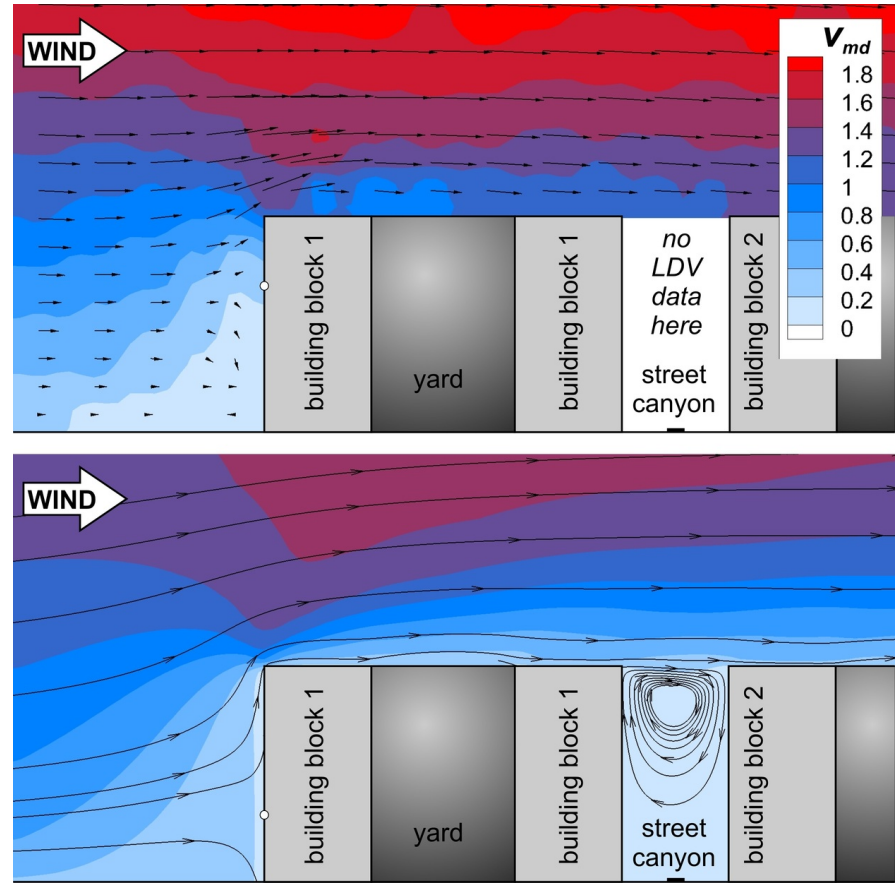

Fig. 7. Velocity field in vertical cross section at the front of the first building block (cross section A-A in Fig. 2). Top: LDV measurement; bottom: CFD simulation, plots coloured by dimensionsless mean velocity magnitude $v_{m d}$

and the detection of vortex cores were performed. The latter method, the velocity gradient eigenmodes method by [41] is based on the critical point theory. In urban environment, the method was successfully applied for the analysis of flow structures in and around a street canyon by [27] and [28].

\section{Results and discussion}

The wind directions investigated show the square in three different situations: wind blows parallel to the long side of the square $(\mathrm{N})$, at slanted 45 degree angle to the long side (NW), and parallel to the short side of the square (W). As the geometry is symmetric, flow field is the same at 0 and 180 , respective at 225 and 315 degree, only concentration fields differ. The simulation results are shown in the following section for comparison with measurement data as plots of dimensionless mean velocity $v_{m d}=\left(u^{2}+v^{2}+w^{2}\right)^{0.5} / u_{H}$ and as plots of normalised concentration $c^{*}$.

\subsection{Vortex core detection}

For the analysis of the complex three-dimensional flow fields acquired by CFD simulation, visualization with 3D streamlines 


\subsection{Northerly wind direction}

Fig. 7 shows a vertical cross section of the velocity field around one of the upstream building blocks at northerly wind direction (the cross section is marked A - A in Fig. 2). In front of the building, a stagnation point can be observed, which is in case of the measurement located higher than in the simulation (at $2 / 3 h$ vs. $1 / 3 h$ ). The difference can be explained by the elevated incoming ABL profile in the wind tunnel measurement (displacement height was $0.5 \mathrm{~h}$ due to the roughness elements), which could not be modelled in the MISKAM simulation.

The separation bubble above the building is both in measurement and in simulation rather small, in simulation even hardly recognisable, due to the stagnation point anomaly [20]: the overproduction of $k$ at the stagnation point in $k-\varepsilon$ turbulence models results in the suppression of separation bubbles on the top/side surfaces of a building. The normalised velocity magnitude $v_{m d}$ above the rooftops past the first leading edge is also under predicted in the simulation.

The velocity field near the ground at $3 \mathrm{~m}$ height is depicted in Fig. 8. Sand erosion results are shown on the left, simulation results on the right. Our observations can be summarised as follows:

- High-speed inflow occurs between the upstream buildings marked by A in Fig. 8

- As a consequence, two symmetrical jets enter the square marked by B.

- Between the two jets, the separation bubble of the centre upstream building block (C) is present, with much lower mean wind speed.

- The majority of the square area is calm $\left(v_{m d}<0.6\right)$, wind speeds are lower than in any of the connecting side streets.

- However, at the foot of the middle downstream building block, a high speed zone develops, possibly caused by the horseshoe vortex around it (marked by D in Fig. 8). This vortex continues in the two southern connecting streets.

- The streamlines in the CFD results and the corner speed-up in the measurement (marked by E) both prove that a significant amount of the air passing the square is forced into the lateral side streets by the aforementioned horseshoe vortex.

- The simulated flow field shows in general highly similar patterns to the sand erosion results.

- However, the horseshoe vortex in the CFD simulation is not properly resolved, and wind velocity magnitudes in the square are in general underestimated by CFD by $30-50 \%$. Similar behaviour was observed inside a street canyon in simulations performed with the same code by [27].

The suppression of the horseshoe vortex by MISKAM can be a less known consequence of the stagnation point anomaly. However, this question can only be answered by a systematic study with more than one CFD model (with different turbulence closures) applied to the problem, which is beyond the scope of this paper.

Fig. 9 shows vortex cores and 3D streamlines in the simulated flow field.

- Downstream of building blocks, vortex cores of upside-down U-shape are formed (A-C in Fig. 9), starting either on the ground or at the lower corner of an upstream building. The vertical part of the $\mathrm{U}$ is a corner vortex driven by the flow in the north-south oriented streets. Air entering these vortices at ground level is elevated upwards. The horizontal part of the U-vortex is the actual street canyon vortex, occupying the upper half of the canyon.

- As mentioned earlier, the horseshoe vortex at E pushes air from the square into the lateral side streets (D).

- A single, large, connected separation vortex appears downstream the whole arrangement $(\mathrm{F})$.

- Rotating vortices can be observed in the inner yards of building blocks $(\mathrm{G})$.

The dispersion field at northerly wind direction is shown in Fig. 10 Our main observations list as follows:

- Concentration decreases exponentially with distance. (Note that the colour scale is logarithmic.)

- The highest concentrations in the square occur in the jets coming from the northern connecting streets and transporting pollutants directly to the square (A in Fig. 10). In the separation bubble of the centre upstream building (marked by B), pollutants are elevated and diluted, thus ground level concentrations are much lower.

- CFD concentrations near the source differ considerably from those measured, the reason for which has been discussed already in Section 3.2. Downstream from the middle of the square (marked by C), CFD predictions agree with measurements very well.

- Very close to the source only CFD data is available, showing extremely high concentrations in the street canyons (D in Fig. 10.

\subsection{North-westerly wind direction}

At the slanted $315^{\circ}$ flow direction (Fig. 11) we can make the following observations:

- Air enters the square coming from all four streets which are on the upstream side of the arrangement. This is visible from corner speed-ups in sand erosion results and from streamlines in the CFD simulation.

- As a consequence, average wind speed in the square is higher than at northerly wind (compare this figure to Fig. 8). 


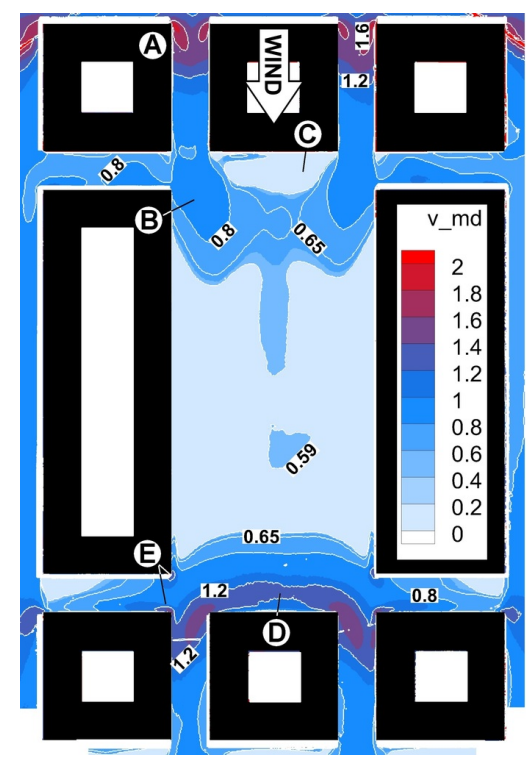

Fig. 8. Velocity field in the square at northerly wind direction at $3 \mathrm{~m}$ height. Left: sand erosion results for dimensionsless mean velocity magnitude $v_{m d}$;

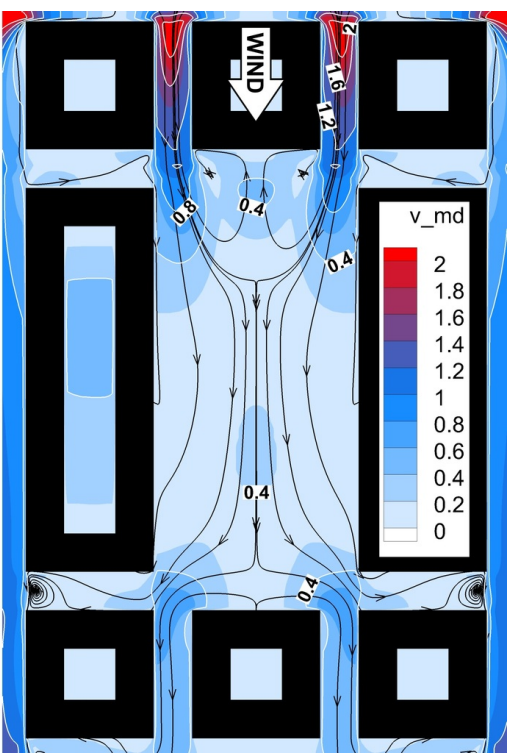

right: CFD simulation results with dimensionsless mean velocity magnitude $v_{m d}$ and streamlines.

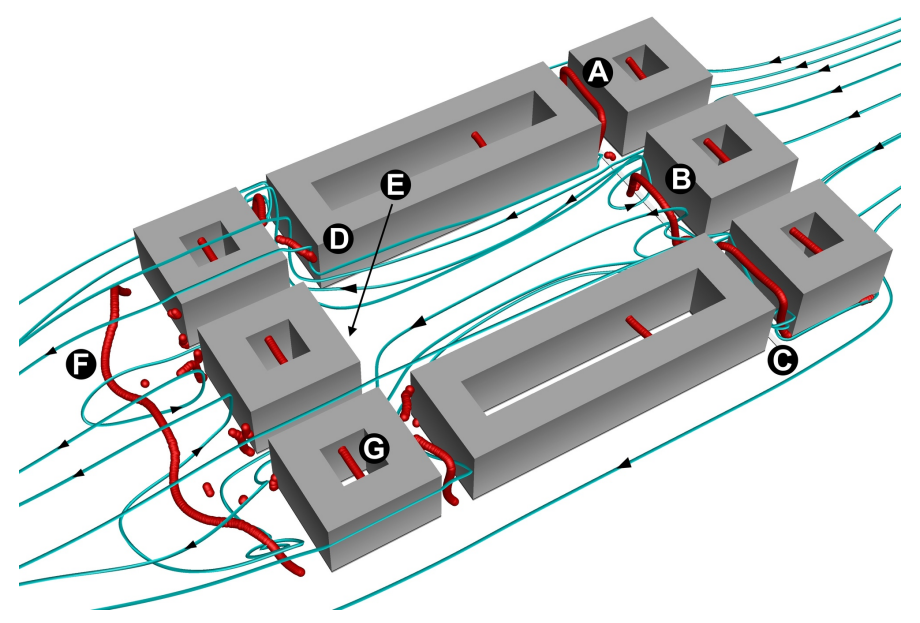

Fig. 9. Vortex cores (thick red curves) and 3D streamlines (thinner cyan lines) at northerly wind direction.

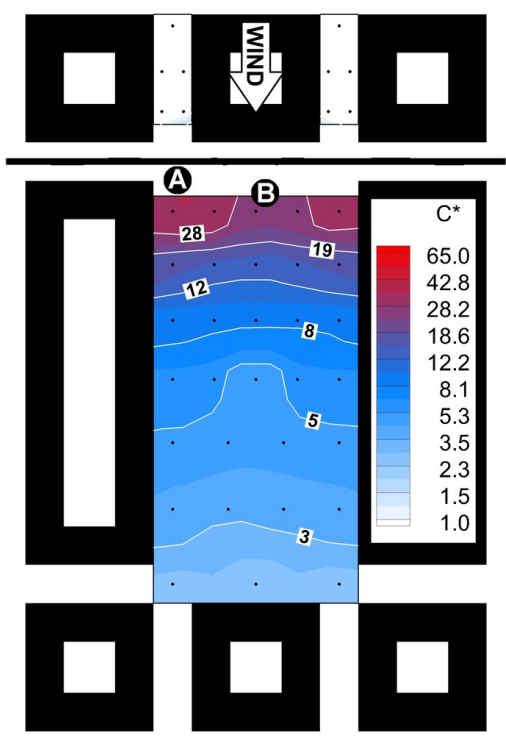

Fig. 10. Concentration distribution in the square at $3 \mathrm{~m}$ height at northerly wind direction. Location of the line source shown with black line. Left: mea-

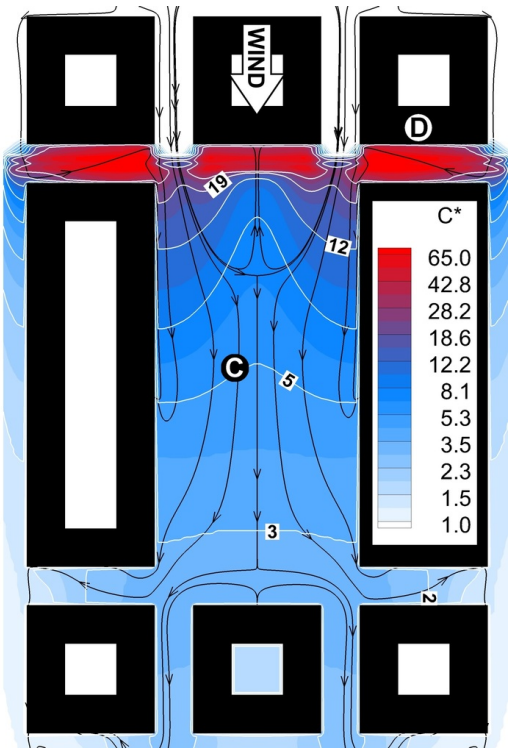

surement. Black dots show the sampling points; right: CFD simulation, with surface streamlines. 

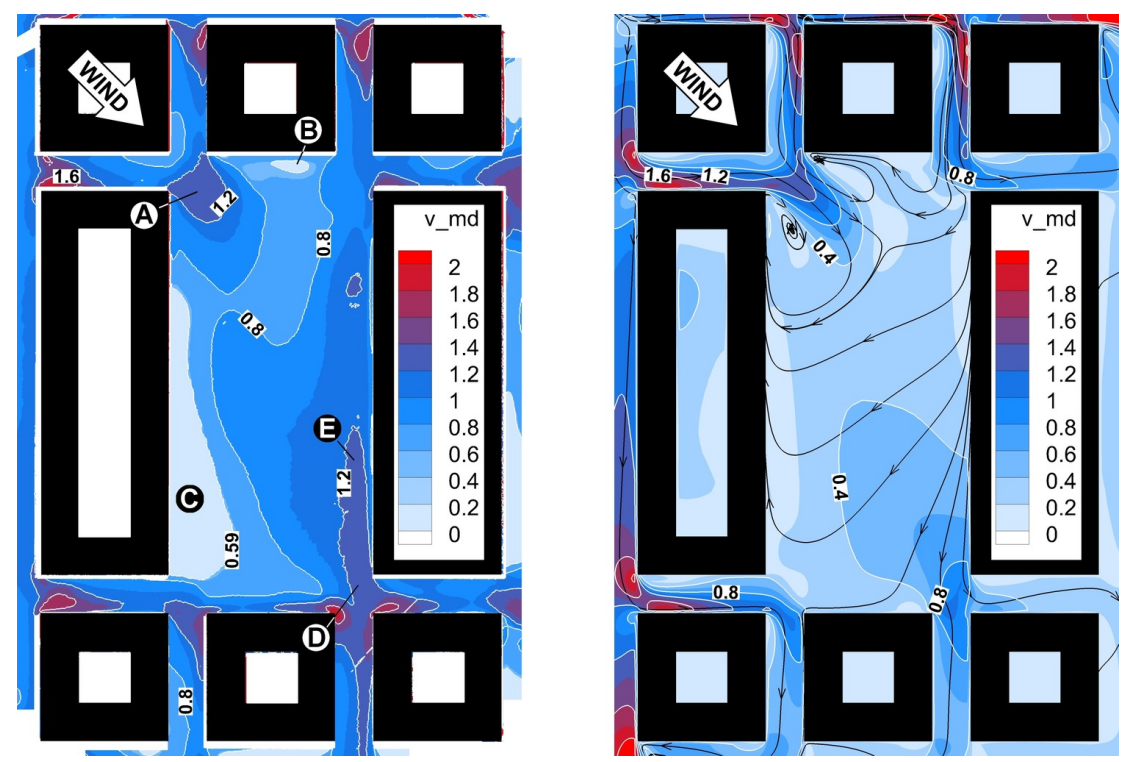

Fig. 11. Velocity field in the square at $3 \mathrm{~m}$ height at northwesterly wind direction. Left: sand erosion results for dimensionsless mean velocity magnitude

$v_{m d}$; right: CFD simulation results with dimensionsless mean velocity magnitude $v_{m d}$ and streamlines.

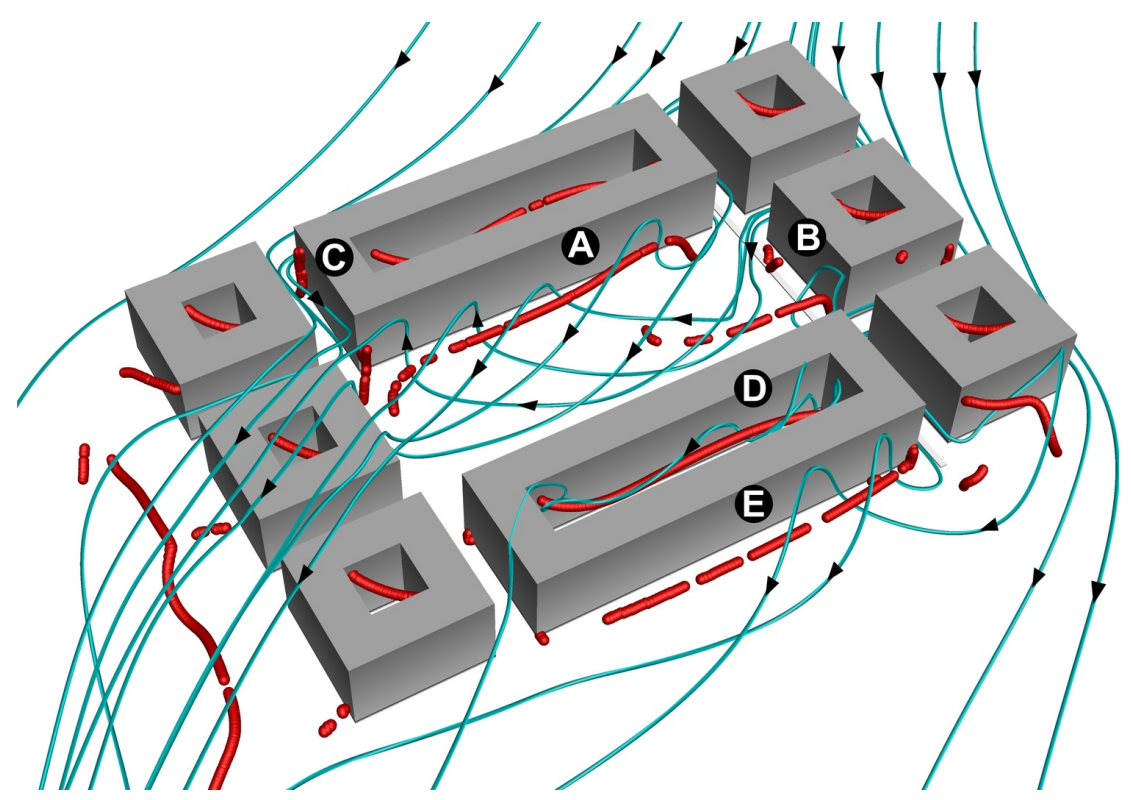

Fig. 12. Vortex cores (thick red curves) and 3D streamlines (thinner cyan lines) at northwesterly wind direction.
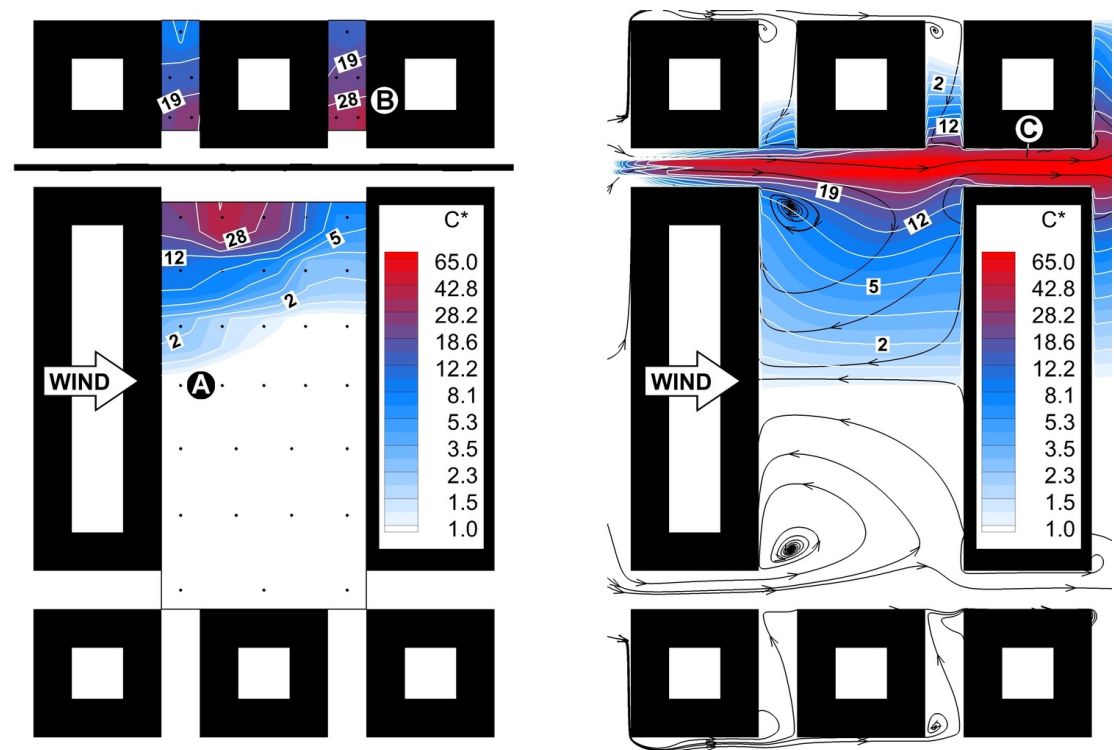

Fig. 13. Concentration distribution in the square at $3 \mathrm{~m}$ height at northwesterly wind direction. Left: measurement; right: CFD simulation. 


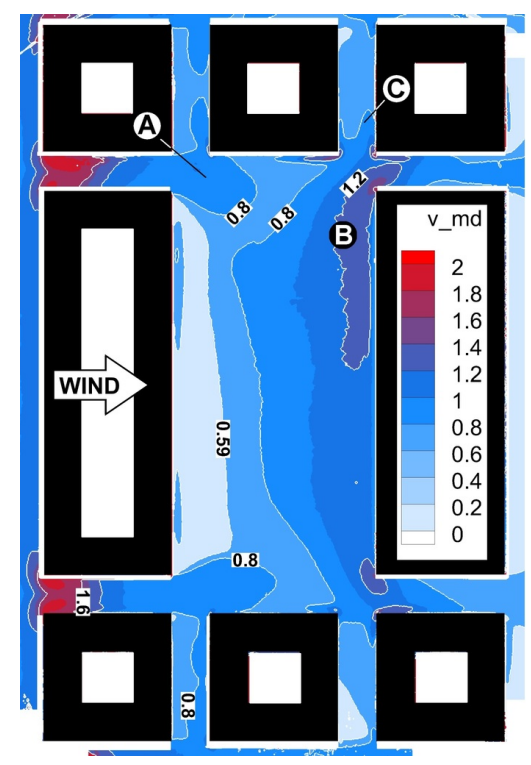

Fig. 14. Velocity field in the square at $3 \mathrm{~m}$ height at westerly wind direction. Left: sand erosion results for dimensionsless mean velocity magnitude

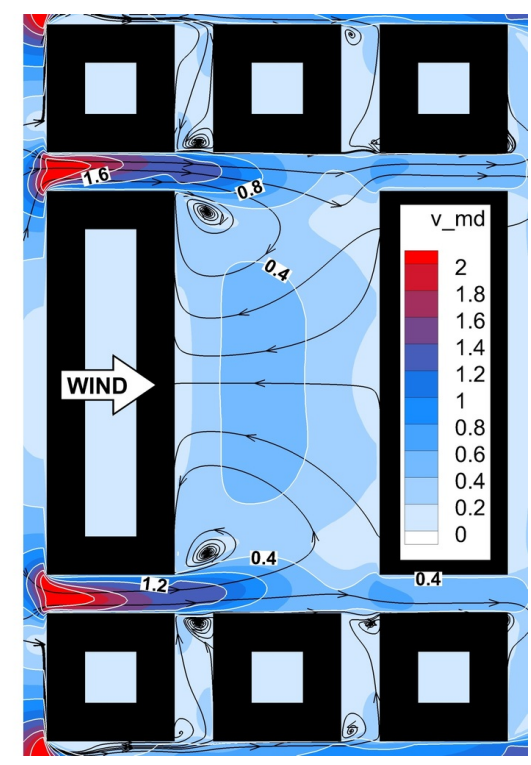

$v_{m d}$; right: CFD simulation results with dimensionsless mean velocity magnitude $v_{m d}$ and streamlines.

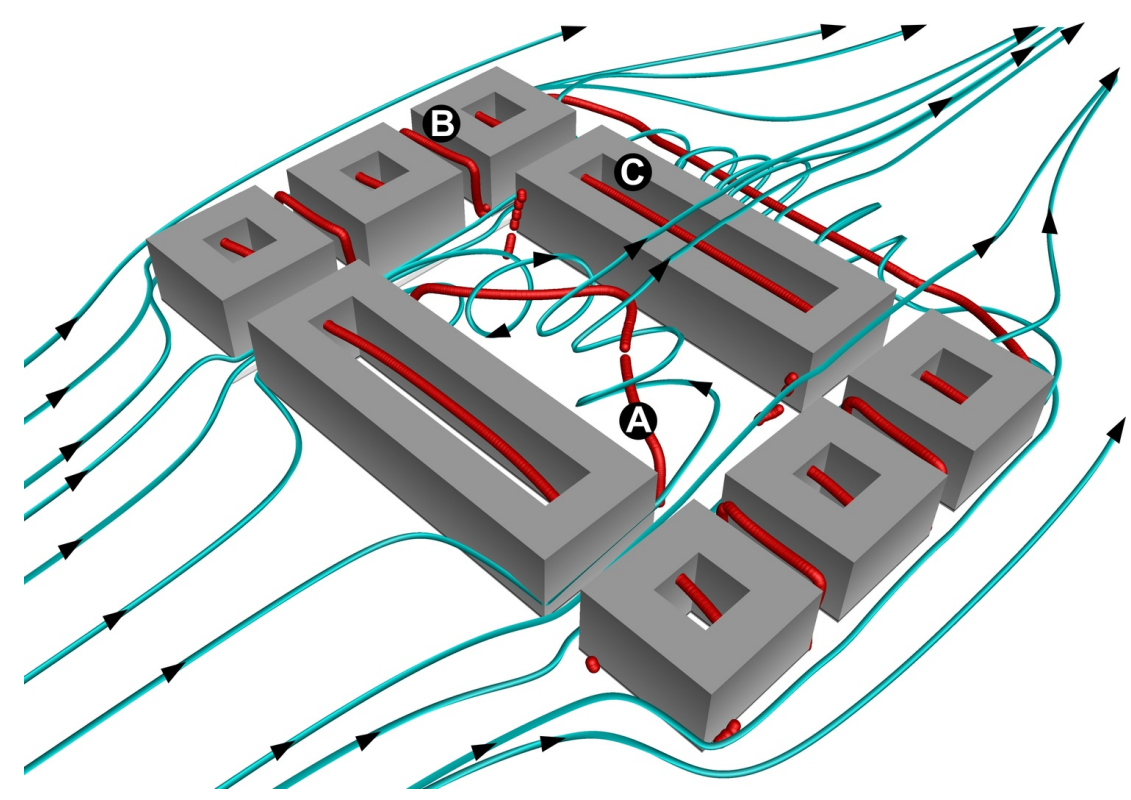

Fig. 15. Vortex cores (thick red curves) and 3D streamlines (thinner cyan lines) at westerly wind direction.
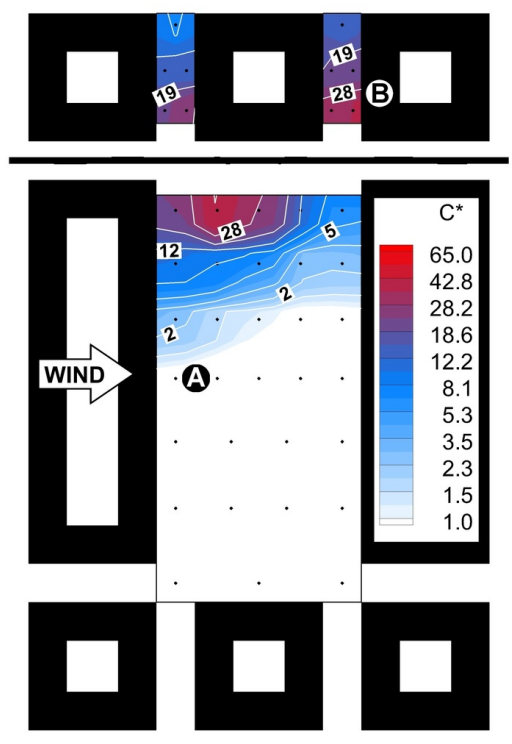
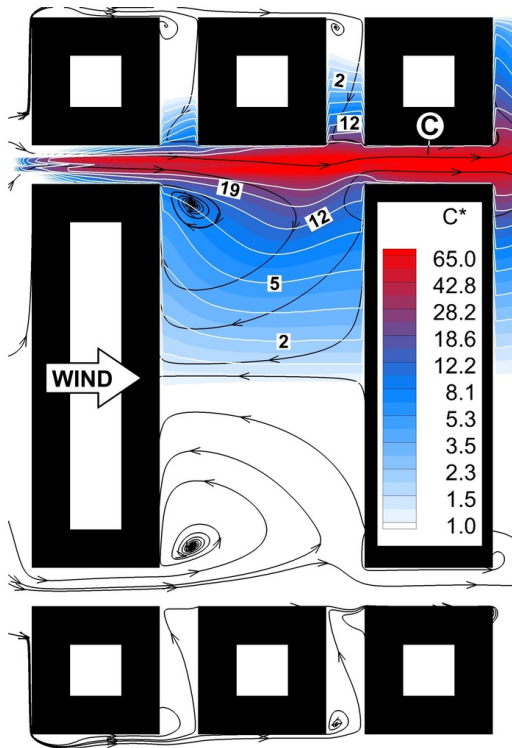

Fig. 16. Concentration distribution in the square at $3 \mathrm{~m}$ height at westerly wind direction. Left: measurement; right: CFD simulation. 
- Peak values of normalised velocity magnitude can be observed in A and D of Fig. 11

- B and C show calm areas, located in the separation zones of the short and of the long upstream building block.

- The long high-speed zone along the long downstream building $(\mathrm{E})$ is the footprint of a front separation vortex. This is unfortunately not resolved by the CFD simulation on the right of Fig. 11 .

- Apart from this, CFD results again show similar flow patterns with underestimated wind speeds. Most notably, surface flow direction in the square is perpendicular to the incident flow direction, approximately towards Southwest.

The vortex cores and 3D streamlines in Fig. 12 give an explanation for this last observation:

- The two separation vortices downstream the long and short upstream block (A and B) result in a helical flow which dominates a large part of the square. The surface portion of this helical flow is responsible for the southwest directed groundlevel flow.

- In the connecting streets, there are no street canyon vortices visible, only corner vortices occur at the inflow (C).

- Because of the slanted flow, other vortices in separation bubbles are also causing helical flow $(\mathrm{D}, \mathrm{E})$.

Fig. 13 shows the consequences of the developed flow field on the concentration distribution near ground level.

- Highest concentration in the square occurs at A (caused by the air jet entering the square across the line source).

- Wind tunnel measurement shows higher concentrations on the western (B) than on the eastern side (C). Responsible for that is the aforementioned helical flow in the square, but also the front separation vortex of the long downstream building contributes to that (E in Fig. 11.

- The lack of the latter structure in the CFD simulation explains why the concentration isolines have not the same shape in the CFD results as in the wind tunnel measurement.

\subsection{Westerly wind direction}

Unfortunately, the sand erosion map at westerly wind (Fig. 14, left) shows some asymmetry, possibly due to a slight error in the incident flow direction. The difference, however, is not significant. With wind direction parallel to the shorter side of the square, several of the observations made at northerly wind direction can be repeated. These are:

- High speed jets are coming from the westerly streets (A in Fig. 14.

- A separation bubble develops with low wind speeds behind the centre upstream building (this is however somewhat larger than at northerly wind).
- A horseshoe vortex appears at the front of the downstream building (B), again inducing flow in the lateral north-south oriented streets $(\mathrm{C})$.

The 3D flow analysis of the CFD results (Fig. 15) shows the separation bubble of the upstream long building block extending to the whole square, and causing upstream reversed flow at ground level (see A in Fig. 14). The aforementioned horseshoe vortex, however, is not resolved by the CFD model.

Concentration maps at westerly wind direction (Fig. 16) show that:

- Pollutants only can reach to the centre of the square and do not reach the southern half (A in Fig. 16).

- Average concentration is much higher in the northern connecting streets than in the square (B in Fig. 16). CFD underpredicts these concentrations, because the horseshoe vortex in front of the downstream building block, which pushes polluted air into these streets, was not properly resolved in the flow simulation.

- CFD results suggest that the highest concentration will occur in the street marked by $\mathrm{C}$ in Fig. 16

\subsection{Other wind directions}

Due to the symmetry of the arrangement, at south-westerly wind $\left(225^{\circ}\right)$, wind field is the same as at north-westerly wind (Fig. 11 and 12), however mirrored to the east-west centre axis. The lower half of the square in those figures corresponds to the upper half of concentration maps shown in Fig. 17(top). Besides a tiny pollution spot marked by $\mathrm{A}$ in Fig. 17 the direction of dispersion is towards the connecting streets $\mathrm{B}$ and $\mathrm{C}$ with very high concentration.

At southerly $\left(180^{\circ}\right)$ wind direction, the concentration map of which is shown in Fig. 17 (bottom), pollution was only measured in the streets downstream (marked with D and E). The pollutant concentrations in these are notably smaller than at southwesterly wind direction (B and C), as the flow is forced into the lateral streets by the horseshoe vortex around the central building block.

\section{Conclusions}

The aim of this study was to identify the major flow and dispersion phenomena in a simplified urban square geometry. A graphical summary of the flow mechanisms is shown in Fig. 18 identifying high and low speed zones, surface wind directions and vortex structures.

The applied methods, sand erosion technique and tracer dispersion measurements, as well as CFD simulations revealed that separation bubbles downstream the bordering buildings dominate the upstream side of the square. Pollutants entering these separation bubbles are elevated, thus despite the low wind speed in these zones, ground-level pollutant concentrations are reduced by the improved vertical mixing. Quite the opposite effect 

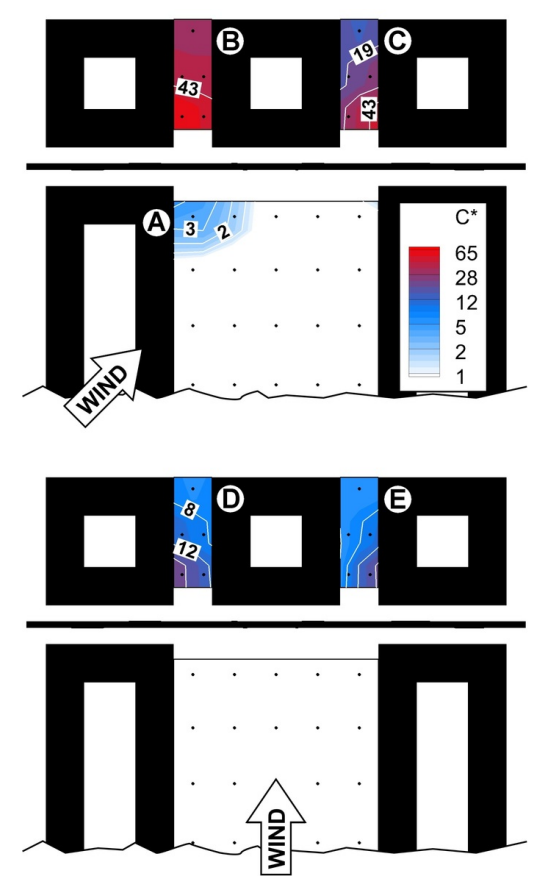

Fig. 17. Concentration distribution in the square at $3 \mathrm{~m}$ height at southwesterly (top) and at southerly (bottom) wind direction. Only the northern part of the square is shown as concentrations in the southern part were below detection
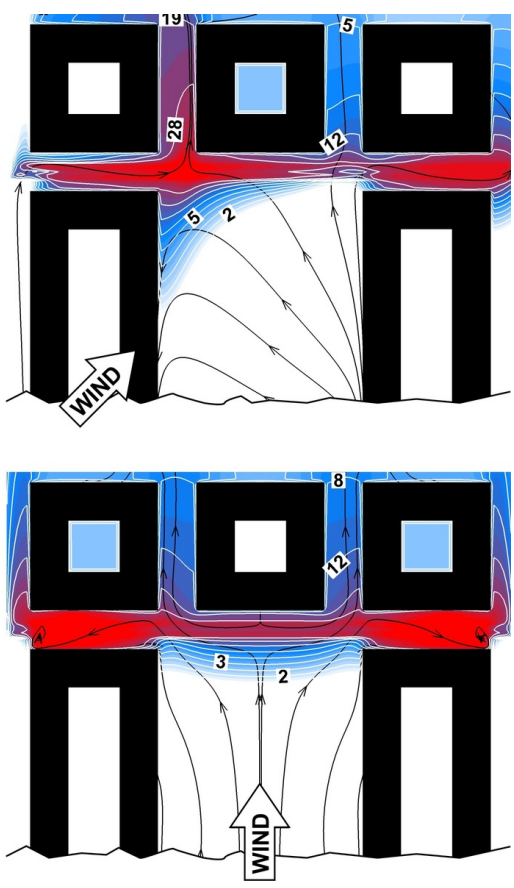

level. Left: measurement; right: CFD simulation. For (mirrored) wind fields see Fig. 10 and Fig. 7

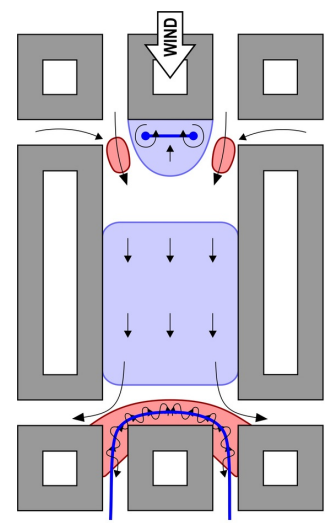

Fig. 18. Flow schematics at various wind directions reconstructed from sand erosion and CFD results. Black arrows: pedestrian level wind directions, thick
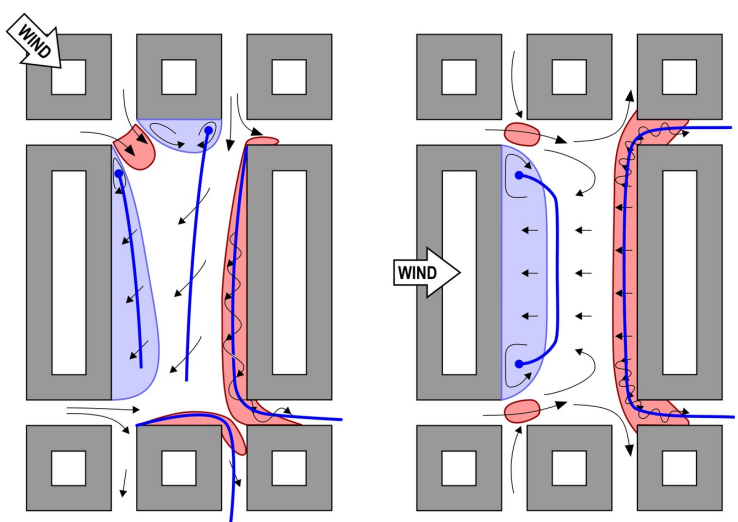

blue lines:vortex cores, purple areas: high wind speed zones near the ground; light blue areas: low wind speed zones near the ground. can be observed at the mouth of connecting upstream streets, where high-speed air jets can transport emissions straight into the square, resulting in local ground-level concentration peaks.

On the downstream side of the square, the horseshoe vortex around the downstream bordering buildings increases local wind speed and improves pollutant removal. The other consequence of this vortex is that it is forcing air into streets perpendicular to the incident flow direction.

At slanted flow direction the downstream separation vortices turn into a large, horizontally adjusted helical vortex dominating the whole square, resulting in ground-level flow direction perpendicular to that of the incoming wind profile. The mentioned horseshoe vortex is present at slanted wind direction, too.

Regarding the concentration fields, the average concentrations in the square are at all wind directions lower than in the neighbouring street canyons with pollutant sources. However, low concentration pollution still can reach the opposite end of the square at specific wind directions. The identification of the aforementioned flow structures was crucial to be able to explain the inhomogeneous concentration patterns observed in the square.

There are many practical consequences from this study. To give a few examples, knowing the prevailing wind direction, and the identified flow structures, the location of air inlets and outlets for ventilation systems can be optimised, the high wind speed areas at the placement of open-air seating or wind-sensitive sport activities can be avoided.

The results of the CFD model applied showed a good agreement with the measurement, with the exception of the horseshoe vortex in front of buildings located on the downstream side of the square. This was not properly resolved by the simulation, leading to under predicted ground level wind speeds, and higher local concentrations. Besides this notable difference, the overall performance of the CFD model allows the investigations 
planned in the future: the study of the actual, complex square geometry, the assessment of the influence of tree plantings in the square, and the analysis of emission reducing traffic measures.

\section{Acknowledgement}

The contributions of MSc students Péter Manninger and Máté Varga are gratefully acknowledged. The project presented in this article is supported by the projects K 108936 "Flow and dispersion phenomena in urban environment" of the Hungarian Scientific Research Fund and the New Széchenyi Plan project TÁMOP-4.2.1/B-09/1/KMR-2010-0002 "Development of quality-oriented and harmonised $R+D+I$ strategy and functional model at BME".

\section{References}

1 Britter RE, Hanna SR, Flow and Dispersion in Urban Areas, Annual Review of Fluid Mechanics, 35, (2003), 469-496, DOI 10.1146/annurev.fluid.35.101101.161147

2 Ahmad K, Khare M, Chaudhry KK, Wind tunnel simulation studies on dispersion at urban street canyons and intersections-a review, Journal of Wind Engineering and Industrial Aerodynamics, 93(9), (2005), 697-717, DOI $10.1016 /$ j.jweia.2005.04.002

3 Belcher SE, Coceal O, Hunt JCR, Carruthers DJ, Robins AG, Atmospheric Dispersion Modelling Liaison Committee Report: ADMLCR7 Annex B: A review of urban dispersion modelling, Atmospheric Dispersion Modelling Liaison Committee (ADMLC), 2013, http: //webarchive.nationalarchives.gov.uk/20131103234051/http: //www.admlc.org.uk/ADMLCReport7.htm

4 Blocken B, 50 years of Computational Wind Engineering: Past, present and future, Journal of Wind Engineering and Industrial Aerodynamics, 129, (2014), 69-102, DOI 10.1016/j.jweia.2014.03.008

5 Gadilhe A, Janvier L, Barnaud G, Numerical and experimental modelling of the three-dimensional turbulent wind flow through an urban square, Journal of Wind Engineering and Industrial Aerodynamics, 46-47, (1993), 755763, DOI 10.1016/0167-6105(93)90349-S

6 Parra MA, Santiago JL, Martín F, Martilli A, Santamaría JM, A methodology to urban air quality assessment during large time periods of winter using computational fluid dynamic models, Atmospheric Environment, 44(17), (2010), 2089-2097, DOI 10.1016/j.atmosenv.2010.03.009

7 Bastigkeit I, Erzeugung von Validierungsdaten für wirbelauflösende mikroskalige Strömungs- und Ausbreitungsmodelle (Generation of validation data for eddy-resolving microscale flow and dispersion models), $\mathrm{PhD}$ thesis, University of Hamburg, 2011, http://ediss.sub.uni-hamburg. de/volltexte/2012/5582/pdf/Dissertation.pdf

8 Hertwig D, Efthimiou GC, Bartzis JG, Leitl B, CFD-RANS model validation of turbulent flow in a semi-idealized urban canopy, Journal of Wind Engineering and Industrial Aerodynamics, 111(0), (2012), 61-72, DOI 10.1016/j.jweia.2012.09.003

9 Rákai A, Kristóf G, Microscale Obstacle Resolving Air Quality Model Evaluation with the Michelstadt Case, The Scientific World Journal, 2013, (2013), Article ID 78174, DOI 10.1155/2013/781748

10 Berbekár É, Harms F, Leitl B, Dosage-based parameters for characterization of puff dispersion results, Journal of Hazardous Materials, 283, (2015), 178-185, DOI 10.1016/j.jhazmat.2014.09.020

11 VDI 3738 Part 12, Environmental meteorology, Physical modelling of flow and dispersion processes in the atmospheric boundary layer - Application of wind tunnels, Verein Deutscher Ingenieure, 2004. Beuth-Verlag, Berlin, Germany.
12 Beranek WJ, van Koten H, Visual techniques for the determination of wind environment, Journal of Wind Engineering and Industrial Aerodynamics, 4(34), (1979), 295-306, DOI 10.1016/0167-6105(79)90009-6

13 Livesey F, Inculet D, Isyumov N, Davenport AG, A scour technique for the evaluation of pedestrian winds, Journal of Wind Engineering and Industrial Aerodynamics, 36(1-3), (1990), 779-789, DOI 10.1016/01676105(90)90075-N

14 Rodrigo JS, van Beeck J, Buchlin J-M, Wind engineering in the integrated design of princess Elisabeth Antarctic base, Building and Environment, 52(0), (2012), 1-18, DOI 10.1016/j.buildenv.2011.12.023

15 Conan B, van Beeck J, Aubrun S, Sand erosion technique applied to wind resource assessment, Journal of Wind Engineering and Industrial Aerodynamics, 104-106, (2012), 322-329, DOI 10.1016/j.jweia.2012.03.017

16 Dezső G, On Assessment of Wind Comfort by Sand Erosion, PhD thesis, Technische Universiteit Eindhoven, 2006.

17 Meroney RN, Pavageau M, Rafailidis S, Schatzmann M, Study of line source characteristics for 2-D physical modelling of pollutant dispersion in street canyons, Journal of Wind Engineering and Industrial Aerodynamics, 62(1), (1996), 37-56, DOI 10.1016/S0167-6105(96)00057-8

18 Balczó M, Szucsán Z, Kalmár G, Goricsán I, Development of Sampling System for Investigations on Pollutant Transport, Fifth Conference on Mechanical Engineering Gépészet 2006., In: Penninger A, Kullmann L, Vörös G (eds.), Proceedings of the Fifth Conference on Mechanical Engineering, Budapest University of Technology and Economics, National Technical Information Centre and Library; Budapest, 2006, http://www.ara.bme.hu/ balczo/publications/ Gepeszet_balczo_et_al2006.pdf CD edition.

19 Eichhorn J, MISKAM Manual for version 6, giese-eichhorn meteorological software; Mainz, Germany, 2011, http://www.lohmeyer.de/de/ system/files/content/download/software/miskam_6_manual_ english.pdf

20 Kato M, Launder BE, The modelling of turbulent flow around stationary and vibrating square cylinders, In: Ninth Symposium on Turbulent Shear Flows, Kyoto, Japan, August 1993, 1993, pp. 10.4.1-10.4.6.

21 López SD, Numerische Modellierung turbulenter Umströmungen von Gebäuden, PhD thesis, University of Bremen, 2002.

22 Eichhorn J, Kniffka A, The Numerical Flow Model MISKAM: State of Development and Evaluation of the Basic Version, Meteorologische Zeitschrift, 19(1), (2010), 81-90, DOI 10.1127/0941-2948/2010/0425

23 VDI 3783, Part 9: Environmental Meteorology. Prognostic Microscale Windfield Models: Evaluation for Flow Around Buildings and Obstacles, Verein Deutscher Ingenieure, 2005. Beuth-Verlag, Berlin, Germany.

24 Balczó M, Eichhorn J, Refined MISKAM simulations of the Mock Urban Setting Test, In: Proceedings of the XXIII. MicroCAD International Scientific Conference, Miskolc, Hungary, 19-20 March 2009, University of Miskolc, 2009, pp. 7-12, http://www.ara.bme.hu/ balczo/ publications/Balczo_Eichhorn_MicroCAD2009.pdf

25 Goricsán I, Balczó M, Czáder K, Rákai A, Tonkó C, Simulation of flow in an idealised city using various CFD codes, International journal of Environment and Pollution, 44(1-4), (2011), 359-367, DOI 10.1504/IJEP.2011.038437

26 Olesen H, Berkowicz R, Ketzel M, Lofstrom P, Validation of $O M L$, AERMOD/PRIME and MISKAM Using the Thompson Wind-Tunnel Dataset for Simple Stack-Building Configurations, Boundary-Layer Meteorology, 131(1), (2009), 73-83, DOI 10.1007/s10546-009-9355-9

27 Balczó M, Gromke C, Ruck B, Numerical modeling of flow and pollutant dispersion in street canyons with tree planting, Meteorologische Zeitschrift, 18, (2009), 197-206, DOI 10.1127/0941-2948/2009/0361

28 Czáder K, Balczó M, Eichhorn J, Modelling of flow and dispersion in a street canyon with vegetation by means of numerical simulation, In: Proceedings of the XXIII. MicroCAD International Scientific Con- 
ference, Miskolc, Hungary, 19-20 March 2009, University of Miskolc, 2009, pp. 47-52, http://www.ara.bme.hu/ balczo/publications/ Czader_Balczo_Eichhorn_MicroCAD2009.pdf

29 Benson J, Ziehn T, Dixon NS, Tomlin AS, Global sensitivity analysis of a 3-dimensional street canyon model-Part II: Application and physical insight using sensitivity analysis, Atmospheric Environment, 42(8), (2008), 1874 1891, DOI 10.1016/j.atmosenv.2007.11.021

30 Donnelly RP, Lyons TJ, Flassak T, Evaluation of results of a numerical simulation of dispersion in an idealised urban area for emergency response modelling, Atmospheric Environment, 43(29), (2009), 4416-4423, DOI $10.1016 /$ j.atmosenv.2009.05.038

31 Belalcazar LC, Clappier A, Blond N, Flassak T, Eichhorn J, An evaluation of the estimation of road traffic emission factors from tracer studies, Atmospheric Environment, 44(31), (2010), 3814-3822, DOI 10.1016/j.atmosenv.2010.06.038

32 Flassak T, Janicke U, Ketzel M, Comparison of ground-level centreline concentrations calculated with the models OML, AERMOD/PRIME, MISKAM and AUSTAL2000 against the Thompson wind tunnel data set for simple stack-building configurations, In: Proceedings of the13th International Conference on Harmonisation within Atmospheric Dispersion Modelling for Regulatory Purposes (HARMO13), Paris, France, 1-4 June 2010, 2010, pp. H13-163, http://www.harmo.org/Conferences/ Proceedings/_Paris/publishedSections/H13-163-abst.pdf

33 Balczó M, Balogh M, Goricsán I, Nagel T, Suda JM, Lajos T, Air quality around motorway tunnels in complex terrain - Computational Fluid Dynamics modeling and comparison to wind tunnel data, Időjárás, 115(3), (2011), 179-204, http://www.ara.bme.hu/ balczo/publications/Balczo_ et_al_2011.pdf

34 Stern R, Yamartino RJ, Development and first evaluation of microcalgrid: a 3-D, urban-canopy-scale photochemical model, Atmospheric Environment, 35(Supplement 1), (2001), 149-165, DOI 10.1016/S13522310(00)00567-7

35 Dixon NS, Boddy JWD, Smalley RJ, Tomlin AS, Evaluation of a turbulent flow and dispersion model in a typical street canyon in York, UK, Atmospheric Environment, 40(5), (2006), 958-972, DOI 10.1016/j.atmosenv.2005.10.017

36 Leuzzi G, Balczó M M., Amicarelli A, Monti P, Eichhorn J, Thomson DJ, Street canyon concentration estimation coupling the RANS model MISKAM and the micromixing Lagrangian model LAGFLUM, In: Proceedings of the13th International Conference on Harmonisation within Atmospheric Dispersion Modelling for Regulatory Purposes (HARMO13), Paris, France, 1-4 June 2010, 2010, pp. 821825, http://www.harmo.org/Conferences/Proceedings/_Paris/ publishedSections/H13-175-abst.pdf

37 Baumann-Stanzer K, Piringer M, Validation of regulatory micro-scale air quality models: modelling odour dispersion and built-up areas, World Review of Science, Technology and Sustainable Development, 8(2), (2011), 203-213, DOI 10.1504/WRSTSD.2011.044217

38 Letzel MO, Flassak T, Angel D., Verbesserung der AUSTAL2000Ergebnisse durch Strömungs- und Turbulenzübernahme aus MISKAM (Improvement of AUSTAL2000 results through adoption of MISKAM flow and turbulence fields), Gefahrstoffe - Reinhaltung der Luft, 72(78), (2012), 329-333, http://www.lohmeyer.de/de/system/files/ content/download/publikationen/letzel_flassak_angel_2012_ gefahrstoffe72.pdf

39 Franke J, Hellsten A, Schlünzen H, Carissimo B, Best practice guideline for the CFD simulation of flows in the urban environment, COST Office, Brussels, 2007, http://www.mi.uni-hamburg.de/fileadmin/files/ forschung/techmet/cost/cost_732/pdf/BestPractiseGuideline_ 1-5-2007-wwW.pdf

40 Kukačka L, Nošek S, Kellnerová R, Jurčaková K, Jaňour Z, Wind Tun- nel Measurement of Turbulent and Advective Scalar Fluxes: A Case Study on Intersection Ventilation, The Scientific World Journal, 2012, (2012), DOI 10.1100/2012/381357

41 Sujudi D, Haimes R, Identification of swirling flow in $3 D$ vector fields, American Institute of Aeronautics and Astronautics, 1995, Report No.:AIAA Paper 95-1715, DOI 10.2514/6.1995-1715 